\title{
Managing Calcified Coronaries: the Bugaboo of Percutaneous
}

\section{Coronary Intervention}

Jaroslaw Heinrich ${ }^{1}$, Baravan Al-Kassou ${ }^{2}$, Heyder Omran ${ }^{3 *}$

${ }^{1}$ Bundeswehrzentralkrankenhaus Koblenz, Klinik I, Rübenacher Str. 170, 56072 Koblenz, Germany

${ }^{2}$ Medizinische Klinik und Poliklinik II, Universitätsklinikum Bonn, Venusberg-Campus 1, 53127 Bonn, Germany

${ }^{3}$ GFO Kliniken Bonn, Robert-Koch-Str. 1, 53115 Bonn, Germany

*Corresponding Author: Debabrata Dash, Department of Cardiology, Zulekha Hospital, Sharjah, UAE

Received Date: February 02, 2021; Accepted Date: March 19, 2021 ; Published Date: March 26,2021

Citation: Debabrata Dash, Sreenivas Reddy, Rohit Mody, Shahid A Merchant., (2021) Managing Calcified Coronaries: the Bugaboo of Percutaneous Coronary Intervention. J. Clinical Cardiology and Cardiovascular Interventions, 4(6); Doi:10.31579/2641-0419/139

Copyright: () 2021 Debabrata Dash, This is an open-access article distributed under the terms of the Creative Commons Attribution License, which permits unrestricted use, distribution, and reproduction in any medium, provided the original author and source are credited.

\begin{abstract}
Background

Percutaneous coronary intervention (PCI) of lesions with heavily coronary artery calcium (CAC) still represents a challenge for interventionists, with increased risk of immediate complications, late failure due to stent underexpansion and malapposition, and consequently poor clinical outcome. In this focused review, we provide the summary of principles, technique and contemporary evidence for various existing and emergent plaque modifying strategies.

Main text

PCI of lesions with heavy CAC still poses a challenge for the interventionists due to an increased risk of incomplete lesion preparation with subsequent suboptimal stent deployment and higher rates of acute and chronic stent failure. With the emergence of many novel devices and technologies, the treatment of lesions with heavy CAC has become increasingly feasible, safe and predictable. It seems likely that combining enhanced intravascular imaging modalities with traditional or new dedicated tools for the treatment of such lesions grant better lesion preparation. This optimizes delivery and deployment of drug-eluting stents translating into improved patient outcome.

Conclusion

The lesions with significant CAC are likely to surge due to aging population and increased rates of diabetes and chronic renal disease. The optimal therapy for such lesions is multi-adjunctive and requires the availability of several modalities including intracoronary imaging which could impact the clinical outcome favourably.
\end{abstract}

Keywords: percutaneous coronary intervention; atherectomy; lithotripsy

\section{Background}

Heavy coronary artery calcium (CAC) poses a real challenge for successful percutaneous coronary intervention (PCI). Treatment of such calcified lesions lead to higher rates of procedural complications, [1] with higher rates of target lesion revascularization (TLR), restenosis, and major adverse cardiac events (MACE). [2-5] Heavily calcified lesions are prone to stent underexpansion and malapposition, which are associated with higher rates of stent thrombosis as well as in-stent restenosis. [6-7] Several strategies and technologies have been crafted to treat CAC with the aim of optimal lesion preparation followed by successful stent deployment. Advances include balloon-based (cutting and scoring balloon, super high pressure balloon and lithoplasty balloon etc) and atherectomy (rotational, laser, and orbital) techniques. Here, the author describes the utility of such modalities in contemporary practice.

\subsection{Pathophysiology of CAC}

$\mathrm{CAC}$ is an active process reflecting a wider systemic inflammatory status, typically observed in patients with metabolic syndrome, diabetes mellitus, or chronic kidney disease. [8,9] It is more common in men older than 70 years of age (>90\% in men vs. $67 \%$ in women). [10] The incidence of $\mathrm{CAC}$ varies according to the imaging modality used. The moderate to severe CAC can be encountered in up to one-third of coronary lesions in coronary angiography (CAG). [11] Atherosclerotic CAC is dysmorphic calcium precipitation created by chondrocyte-like cells and linked to expression of inflammatory factors, such as cytokines released by tissue macrophages and foam cells. It is likely that inflammation precedes calcification and plays an important role in its progression, with the two processes coexisting and promoting each other. [12] CAC is commonly associated with larger plaque burden, multivessel disease and a greater degree of lesion complexity including involvement of coronary 
bifurcation or chronic total occlusion. ${ }^{11}$ Moreover, specific patterns of $\mathrm{CAC}$, such as calcified nodules and coronary microcalcifications, are related to plaque instability and vulnerability. [13] Typically, these lesions are challenging to cross with standard devices and are less likely to respond to conventional balloon dilatation. Inevitably, inadequate lesion preparation before stenting increases the risk of stent loss, stent underexpansion/fracture and the rate of intraprocedural complications, such as no reflow, coronary dissection, or perforation. [11] Interestingly, the passage of drug-eluting stents (DES) through areas of heavy CAC has also been related to polymer damage with consequent impairment of drug elution.

\subsection{Imaging techniques}

\subsubsection{Coronary computed tomography angiography}

Coronary computed tomography angiography (CCTA) is the most important non-invasive imaging technique used. CAC is depicted as an area of hyperattenuation, defined as an area of at least $1 \mathrm{~mm}^{2}$ with $>130$ Hounsfield units or $\geq 3$ adjacent pixels using the Agatston method. [14] A CAC score is calculated using a weighted value assigned to the highest density of calcification in each coronary segment that is multiplied by the area and summed finally for all arteries to give a total coronary calcium score correlated with the patient outcomes. [15] This score carries a strong prognostic factor for clinical events in the mid to long term in asymptomatic population. CCTA may uncover spotty calcification which is designated one of the signs of plaque vulnerability. This modality allows accurate identification and localization of calcium along coronary arteries thereby improving procedural success of PCI.

\subsubsection{Coronary angiography}

Coronary angiography (CAG) is often limited by underestimation of calcium, inaccurate grading, and inability to assess calcium depth within
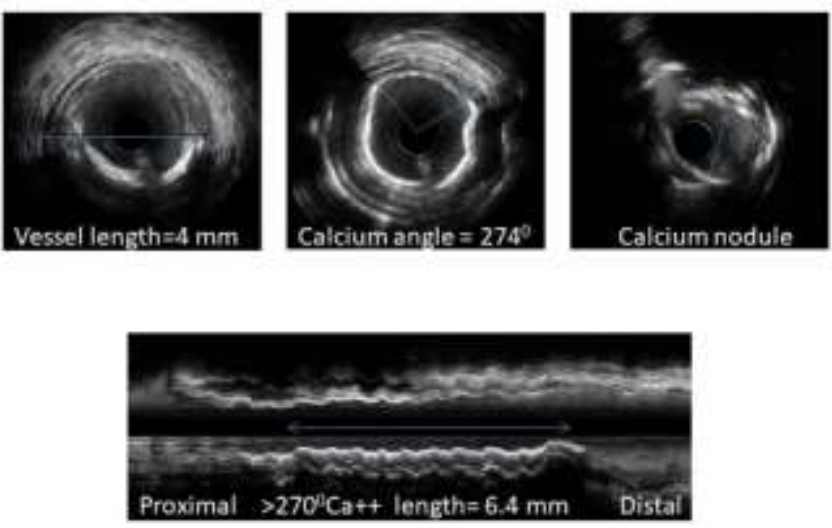

Figure 1: Intravascualr ultrasound depicting indicators calcium score (calcium length, angle, nodule and vessel diameter)

\subsubsection{Optical coherence tomography}

CAC is designated as signal-poor or heterogeneous region with sharp delineated borders in Optical coherence tomography (OCT). Unlike IVUS, where CAC is most often confused with dense fibrous tissue, OCT detected CAC very often simulates lipid or necrotic core; however, the signal-poor regions of CAC are sharply delineated whereas the signalpoor regions of lipid or a necrotic core have poorly defined or diffuse the plaque. CAC is classified as none or mild, moderate, or severe. The radiopacity observed only during the cardiac cycle before injection of contrast medium defines moderate CAC. Severe CAC is delineated as radiopacity observed without cardiac motion, visible on both sides of the arterial lumen, as a double track. [11] The calcium content tends to appear as hazy areas with inhomogeneous contrast staining and hence the differentiation from thrombus is difficult using CAG only. CAG is able to determine CAC only in $38 \%$ of cases and the identification seems to be dependent on the degree of the arch of calcification $(60 \%$ for moderate and $85 \%$ for severe CAC) as demonstrated by Mintz et. [16]

\subsubsection{Intravscular ultrasound}

The hallmark of CAC on intravascular ultrasound (IVUS) is an echodense plaque that is brighter than reference adventitia with acoustic shadowing. One of the limitations of IVUS is that dense fibrous tissue may also cast a shadow similar to CAC. CAC brings about reverberations in contrast to dense fibrous tissue. IVUS enhances the sensitivity to in detect CAC significantly compared with CAG $(73 \%$ of cases vs. $38 \%$; $p<0.001)$. [16] Quantitatively (the arc of lesion), CAC has been classified into 4 classes on IVUS: Class I, $0^{\circ}-90^{\circ}$ calcification; Class II, $91^{\circ}-180^{\circ}$ calcification; Class III, $181^{\circ}-270^{\circ}$ calcification; and Class IV $>270^{\circ}$ calcification. [17] Semiquantitative grading classifies CAC as absent or subtending 1, 2, 3, or 4 quadrants. IVUS determines abluminal calcified deposits within the deeper layers (media or adventitia) of the vessel wall. It allows only definition of the calcific arch, without offering insights into accurate thickness of CAC because of acoustic shadowing. Maximum circumferential extension of calcium $>180^{\circ}$ is linked to possible stent underexpansion. An IVUS CAC score (Figure 1) of $\geq 2$ (2 points for calcium length $>270^{\circ}>5 \mathrm{~mm}, 1$ point each for calcium nodule, smaller vessel diameter $(<3.5 \mathrm{~mm})$ and reverberation $\left.<90^{\circ}\right)$ emerges as a relevant predictor for stent underexpansion warranting adjunctive device. [18] 


\begin{tabular}{|c|c|c|}
\hline Modalities & Merits & Demerits \\
\hline CAG & $\begin{array}{l}\text { - Detection of calcium location along coronary } \\
\text { vessel } \\
\text { - Optimal detection of severe CAC }\end{array}$ & $\begin{array}{l}\text {-Invasive technique } \\
\text { - Contrast medium } \\
\text { - Low sensitivity } \\
\text { - Only qualitative grading of calcium } \\
\text { - Poor depiction of mild to moderate CAC } \\
\text { - Detection of moderate CAC only during } \\
\text { the cardiac cycle } \\
\text { - Inability to assess CAC thickness }\end{array}$ \\
\hline CTCA & $\begin{array}{l}\text {-Non-invasive technique } \\
\text { - Calcium score in asymptomatic individuals } \\
\text { - Prognostic role of CAC score } \\
\text { - Detection of calcium location along coronary } \\
\text { vessels } \\
\text { - Detection of spotty calcifications }\end{array}$ & -Contrast medium \\
\hline IVUS & $\begin{array}{l}\text { - No contrast medium } \\
\text { - Detection of superficial and deep CAC } \\
\text { - Semiquantitative grading of CAC: } \\
\text { distribution, localisation, length, arc }\end{array}$ & $\begin{array}{l}\text {-Invasive technique } \\
\text { - Deep calcium is hidden by acoustic } \\
\text { shadow } \\
\text { - Non-visualization of microcalcifications } \\
\text { - Inability to assess CAC thickness }\end{array}$ \\
\hline OCT & $\begin{array}{l}\text {-Superior resolution } \\
\text { - Calcium thickness can be measured } \\
\text { - Quantitative grading of calcium: distribution, } \\
\text { localisation, thickness, length, area, volume } \\
\text { - Optimal detection of microcalcifications }\end{array}$ & $\begin{array}{l}\text { - Invasive technique } \\
\text { - Contrast medium } \\
\text { - Poor depth penetration }\end{array}$ \\
\hline
\end{tabular}

CAC: coronary artery calcium; CAG: Coronary angiography; CCTA: Coronary computed tomography angiography; IVUS: intravascular ultrasound; OCT: Optical coherence tomography

\section{Table 1: Comparisons of imaging techniques in for the detection of CAC}

\subsection{Treatment modalities}

A key concept in approaching heavily CAC involves facilitation of lesion crossing and plaque modification. The support wires, buddy wires, guide extensions, lesion predilatation and anchoring of the guide catheter with inflation of a second balloon in a side branch or distal vessel are possible means for lesion crossing. The underlying calcified plaque gets modified using the dedicated balloon-based (Table 2) and/or ablation (Table 3) devices.

\begin{tabular}{|c|c|c|}
\hline Device & Technical features & Mechanism of action \\
\hline $\begin{array}{l}\text { Super high pressure balloon (OPN NC } \\
\text { (SIS-Medical AG, Winterthur, } \\
\text { Switzerland) }\end{array}$ & 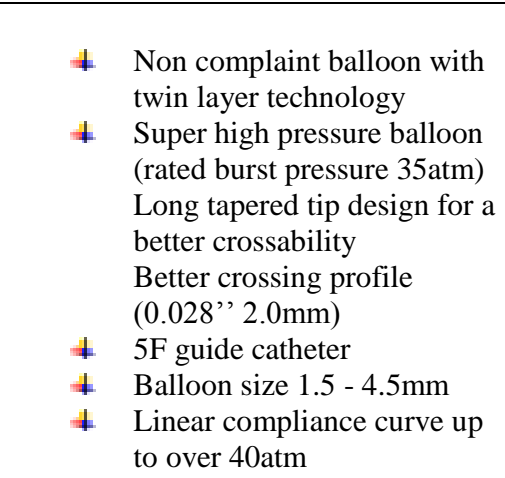 & $\begin{array}{ll}\text { \# } & \text { Super high pressure inflation } \\
* & \text { Uniform expansion } \\
& \text { Zero "dog-boning." }\end{array}$ \\
\hline $\begin{array}{l}\text { Constrained semi-compliant balloon } \\
\text { (Chocolate }^{\mathrm{R}} \text { (TrirReme Medical, } \\
\text { Pleasanton, CA, USA) }\end{array}$ & $\begin{aligned} &+ \text { An over-the-wire balloon } \\
& \text { catheter } \\
& \# \text { Nitinol constraining structure } \\
& * \text { Unique dilatation pillow and } \\
& \text { grooves } \\
&+\quad \text { Balloon size } 2.0-3.5 \mathrm{~mm}\end{aligned}$ & $\begin{array}{l}+\quad \text { Controlled, predictbale and } \\
\text { uniform inflation } \\
+\quad \begin{array}{l}\text { Enhanced dispersion of } \\
\text { dilatation forces }\end{array} \\
+\quad \text { Reduced "dog-boning" }\end{array}$ \\
\hline
\end{tabular}




\begin{tabular}{|c|c|c|c|c|}
\hline & 4 & $5 \mathrm{~F}$ guide catheter & & \\
\hline $\begin{array}{l}\text { Cutting balloon (Wolverine }{ }^{\mathrm{TM}} \text { (Boston } \\
\text { Scientific, Natick, MA, USA) }\end{array}$ & $\begin{array}{l}+ \\
4 \\
4 \\
\end{array}$ & $\begin{array}{l}\text { Nylon non-compliant balloon } \\
\text { Microsurgical blade, called: } \\
\text { "Atherotome" (functional } \\
\text { height: } \sim 0.005 " \text { ) } \\
\text { Balloon size } 2.0-4.0 \mathrm{~mm} \\
\text { Working range } 8-16 \mathrm{~atm} \\
\text { 5F Guide catheter }\end{array}$ & $\begin{array}{l}4 \\
4 \\
4\end{array}$ & $\begin{array}{l}\text { Radial incisions ( } 3 \text { or } 4) \\
\text { through calcific tissue } \\
\text { Avoidance of balloon } \\
\text { slippage } \\
\text { More uniform balloon } \\
\text { expansion }\end{array}$ \\
\hline $\begin{array}{l}\text { Scoring balloon (AngioSculpt }{ }^{\mathrm{R}} \\
\text { (AngioScore, Inc., Fremont, CA, USA) }\end{array}$ & $\begin{array}{l}+4 \\
4 \\
4 \\
4 \\
4 \\
4 \\
4\end{array}$ & $\begin{array}{l}\text { Semi-compliant balloon } \\
\text { Nitinol-enhanced balloon } \\
\text { deflation } \\
\text { Electropolished, rectangular, } \\
\text { spiral scoring element } \\
(\sim 0.005 ") \\
\text { Balloon size } 2.0-3.5 \mathrm{~mm} \\
\text { Working range } 2-20 \mathrm{~atm} \\
\text { Crossing profile } 0.047 " \\
6 \text { F Guiding catheter }\end{array}$ & 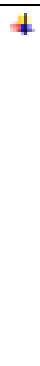 & $\begin{array}{l}\text { Large and predictable luminal } \\
\text { expansion by rectangular } \\
\text { nitinol scoring edges. }\end{array}$ \\
\hline $\begin{array}{l}\text { Intravascular lithotripsy (Shockwave } \\
\text { Coronary Rx Lithoplasty System, } \\
\text { Shockwave Medical, Santa Clara, } \\
\text { California) }\end{array}$ & $\begin{array}{l}4 \\
4 \\
4 \\
4 \\
4\end{array}$ & $\begin{array}{l}\text { Semi-compliant balloon } \\
\text { A series of unfocused, } \\
\text { electrohydraulic lithotripsy } \\
\text { emitters } \\
\text { Balloon size } 2.5-4 \mathrm{~mm} \\
\text { Inflated to } 4 \mathrm{~atm} \text { and } \\
\text { administered } 4 \text { cycles of } 10 \mathrm{~s} \\
\text { Crossing profile } 0.044 \text { ', } \\
\text { 6F Guiding catheter }\end{array}$ & + & $\begin{array}{l}\text { Transient acoustic } \\
\text { circumferential pressure } \\
\text { pulses. }\end{array}$ \\
\hline
\end{tabular}

Table 2: Balloon based plaque modification strategies (Ref)

\section{Advantages}

$>$ More controlled means of calcium modification

$>$ Circumferential calcium modification (due to elimination of wire bias).

$>$ Apparent lack of embolization and no reflow compared with atherectomy

$>$ Apparent lack of perforation

$>$ Ability to modify calcification without further vessel injury with minimal trauma on soft tissue

$>$ Less technically demanding and reduced learning curve

Favourable for kissing balloon technique

\section{Disadvantages}

$>$ Difficult negotiation and delivery of the balloon to the target lesion due to higher crossing profile.

$>$ Sometimes, inability to cross the lesion without the need for atherectomy

Table 3: Advantages and disadvantages of intravascular lithotripsy

\subsubsection{Balloon-based strategies}

\subsubsection{High and super high pressure non-complaint balloons}

A non-complaint (NC) balloon may be the first choice in mild to moderate calcified stenosis with restricted calcium arc $\left(<90^{\circ}\right)$. However, the risk of eccentric balloon expansion because of the increased hoop stress conferred by severe CAC, is not fully mitigated by NC balloon. The focal points of resistance within a lesion result in nonuniform balloon expansion and "dog boning" with hyperexpansion in the more compliant segments of the vessel without fracturing the calcium.

Super high-pressure balloon technology incorporates a rapid-exchange NC balloon (OPN Sys Medical, Frauenfeld, Switzerland) with a twinlayer structure allowing inflation pressure up to 35 to $40 \mathrm{~atm}$ without bursting of the balloon (Table 2). This is considered as not only effective but also safe approach when experiencing extremely calcified lesions 
undilatable by conventional high-pressure NC balloon. Although this balloon can be used both before and after stent implantation, most evidence confirms safety and efficacy during post stenting dilation. The unique twin-layer technology ensures uniform balloon expansion over a wide range of pressures, reducing the risk of balloon rupture, vessel damage and coronary perforation. [21] The main limitation of the OPN $\mathrm{NC}$ balloon is its relatively high profile which, together with the stiffness of the twin-layer technology, undermines any attempt to recross when inflated. Guide extension catheter may assist successful delivery of such balloon. [22]

\subsubsection{Cutting and scoring Balloons}

The cutting balloon ([Flextome $\left.{ }^{\mathrm{TM}}\right]$, Boston Scientific, Natick, MA, USA) is a semi-compliant monorail over-the-wire (OTW) balloon with 3 or 4 microtomes mounted on its body, designed to cut the continuity of fibrocalcific plaque creating fissures on the plaque. The cutting balloon ensures a more controlled lesion predilation with less adjacent vessel wall trauma and less risk of dissection. The presence of cutting elements on the surface of the balloon allows effective dilation with a lower inflation pressure (Figure 2).

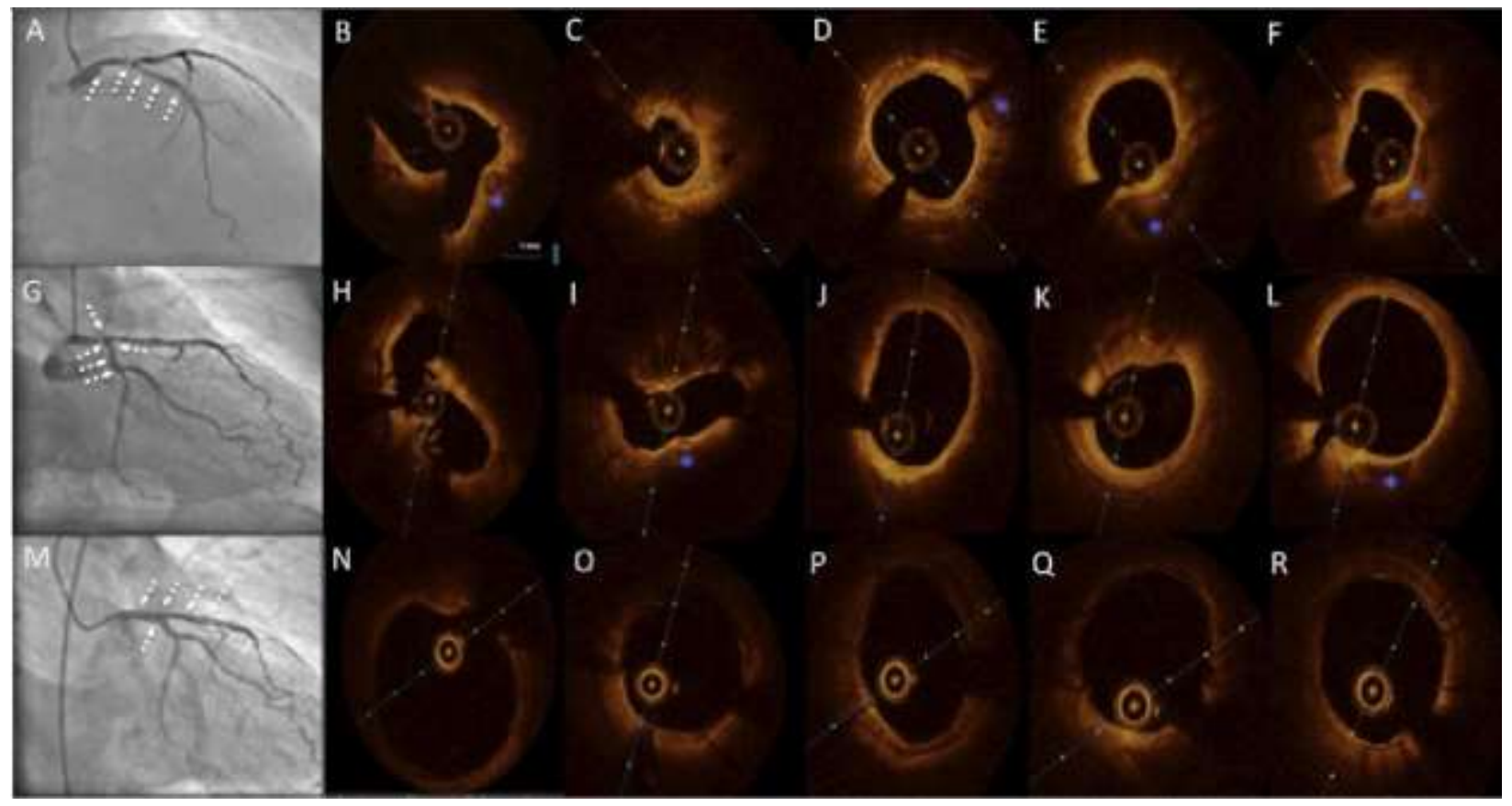

A-F: Baseline lesion in left anterior descending (LAD)

$B-F$ : Baseline lesion in left circumflex

M-R: Final result following modification of calcified plaque by cutting balloon and left main bifurcation stenting.

$\square$ Calcification

A, G, M: Angiographic images

$B-F, H-L, N-R$ : OCT images

Figure 2. Depiction of the effects of cutting balloon on heavy coronary calcium by optical coherence tomography (OCT)

The microblades also prevent the balloon slippage is prevented by the microblades. One randomized trial failed to show a superiority of cutting balloon for type A/B lesions compared with standard balloons. [23] An IVUS-based study [24] indicated that cutting balloon achieves larger luminal gain compared to conventional balloon. It is limited by high rigidity that hinders lesion navigation through tortuous and calcified vessels. With its most recent iteration (Wolverine) the atherotome's support thickness has been reduced, without affecting the functional height of the blade, resulting in an overall smaller crossing profile and improved crossability.

The principle of using a "buddy wire" to fracture calcified plaque promoted the development of the scoring balloon: a low-profile semicompliant balloons with a scoring element on the surface
(AngioSculpt, Biotronik, Berlin Germany; Scoreflex OrbusNeich, Hong Kong, China; NSA Alpha BBraun, Melsungen, Germany). [25] During inflation, the radial force is mainly exerted on the scoring element and this is transmitted to the vessel wall causing plaque fissuration (Table 2). The embedded nitinol element ensures anchoring of the balloon with a lower risk of "melon-seeding" effects and a lower risk of dissection and perforation. It is likely that prolonged inflation might improve the device navigation with a "creep phenomenon": a sustained tensile load ensuring microcrack formation and propagation leading to a phasic tissue elongation. [26] Scoring balloons have been considered as an alternative to cutting balloons in moderate calcification and, in recent years, have been preferred due to superior flexibility and deliverability, although no specific randomised control trials exist in the literature so far. 


\subsubsection{Constrained semi-compliant balloon (chocolate balloon)}

The chocolate ${ }^{\mathrm{R}}$ balloon (TrirReme Medical, Pleasanton, CA, USA) is an OTW balloon with a mounted nitinol constraining structure specifically designed for uniform, controlled inflation and a rapid deflation ensuring an atraumatic dilatation obviating the need for cutting or scoring balloons (Table 2). The nitinol constraining structure generates balloon segments or "pillows" that make contact with the vessel and functions to minimize local forces. The "grooves" promote plaque modification. The distinctive pillows and grooves minimize vessel trauma, reduce the rate of dissection. [22]

\subsubsection{Intravascular lithotripsy}

Intravascular lithotripsy (IVL) is the most recent armamentarium for the treatment of lesions with heavy CAC. It delivers localized pulsatile sonic pressure waves, modifying preferentially calcific plaque without affecting the soft tissue, and subsequently promoting stent delivery and optimization. [27] The balloon catheter with multiple lithotripsy emitters is negotiated over a guidewire to the target lesion. The balloon is attached to the external pulse generator. With balloon inflation at low pressure (4 atm), a burst of 10 pulses of high energy is delivered over 10 seconds followed by further balloon inflation at 6 atm for 15-20 seconds before deflation. This process can be repeated to a total of 8 cycles per balloon (80 pulses). The balloon sizing is based on the desired stent size for that target lesion (ie, 1:1 for the reference vessel diameter) and is often guided by intracoronary imaging. [28] The IVL balloons are all $12 \mathrm{~mm}$ long with diameters ranging from $2.5 \mathrm{~mm}$ to $4.0 \mathrm{~mm}$. Guide catheter extenders and buddy wire support may be required for deliverability and positioning of this large profile balloon.

By inducing calcium fractures (as assessed with IVUS or OCT)., [29-31] the IVL therapy achieves optimal stent expansion in undilatable specialty balloons and rotational atherectomy (RA) refractory lesions. The navigation of IVL balloon could be impacted by severe tortuosity or angulation, critical lumen reduction, plaque indentation into the lumen and a small vessels and multiple stent layers. Up to $46 \%$ of the lesions might also require dedicated lesion predilatation and/or post-dilatation with NC balloons or could benefit from other adjunctive devices such as cutting or scoring balloons or atherectomy to either facilitate balloon delivery or increase calcium compliance after IVL therapy. [30,32] IVL targets CAC circumferentially and thus avoids guidewire bias. Reduced learning curve, apparent lack of embolization and perforation are all very attractive attributes of IVL as compared to atherectomy (Table 3). [22] Furthermore, IVL is possible following stenting. Unlike RA, IVL can be used with more than one guidewire to protect side branches. Because of the presumed ability to pass across a second balloon, IVL can be used with the kissing balloon technique.

This modality can cause vessel complications although balloon rupture is uncommon. The sudden balloon burst has been described with arterial dissection during lithotripsy therapy. Recently there is a case report of perforation following this therapy. ${ }^{33}$ Furthermore, vessels with a diameter $>4 \mathrm{~mm}$ (maximum shockwave balloon size) or important plaque eccentricity preclude appropriate IVL balloon apposition to the vessel wall, and may reduce the efficacy of the therapy. IVL could be safely performed with high procedural success, minimal complications with substantial calcific plaque fracture in most lesions in a prospective multicenter Disrupt CAD II study. [34]

\subsubsection{Atherectomy or ablative devices}

A strategy of debulking calcified lesions as a part of bail-out technique to address heavy CAC has evolved into a primary lesion preparation approach called primary atherectomy in contemporary practice. Compared to bail-out strategy, the primary atherectomy is associated with decreased procedural and fluoroscopy times, contrast volume, and the number of predilatation balloon catheters used. [35] This alters plaque morphology, inflicting fractures in heavy CAC and changing lesion compliance, to increase the likelihood of maximal MLD and complete stent expansion.

\subsubsection{Rotational atherectomy}

Rotational atherectomy (RA [Boston Scientific, Marlborough, Massachusetts]) system is composed of a high-speed rotating diamondcoated burr aimed to act as an abrasive rotatory surface against calcific plaque. The elliptic-shaped metallic burr is available in different sizes (from 1.25 to $2.5 \mathrm{~mm}$ ) and is mounted over an advancer (RotaLink) driveshaft connected to a motor that converts compressed gas into rotational energy. The burr is advanced over a Rotawire (dedicated 0.009-inch 325 $\mathrm{cm}$ long wire) designed to maximize flexibility and to minimize wire bias. The recently introduced RotaPro (Boston Scientific) represents an updated iteration and it offers a better user interface and controls integrated on the advancer. Applying the principle of "differential cutting" RA acts preferentially the fibrocalcific plaque tissue while sparing elastic tissue (Figure 3). 


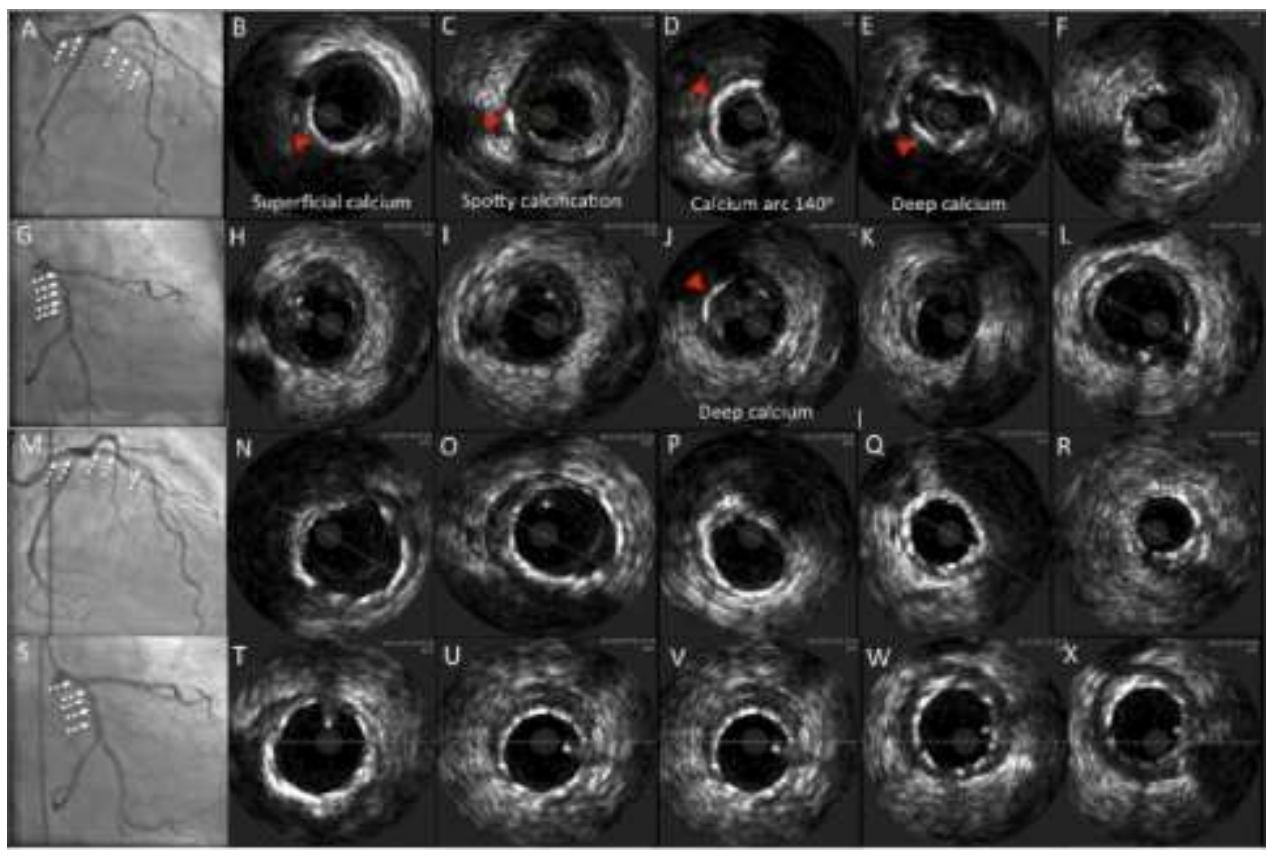

A-F: Baseline lesion in left anterior descending (LAD)

G-L: Baseline lesion in left circumflex (LCX)

$M-R$ : Final result after $R A$ followed by left main bifurcation stenting

$S$-X: Final result after RA followed by left main bifurcation stenting

A, G, M, S: Angiographic images

$B-f, H-L, N-R, T-X$ : IVUS imaging

Figure 3. Intravascular ultrasound (IVUS) depiction of the effects of rotational atherectomy (RA) on heavy coronary calcium

The ablated tissue is pulverized in 5 to $10 \mathrm{~mm}$ debris, which are released into the distal coronary microcirculation. This is the likely mechanism underlying the potential for transient slow/no reflow following RA. [36] The wiring technique has been facilitated by the use of a regular workhorse wire or hydrophilic wire subsequently exchanged over microcatheters or OTW balloons with the rotawire. The RA results are affected by CAC eccentricity, vessel luminal area, burr size and wire bias degree. [37] An optimal scenario for RA in terms of predictable luminal gain is a lesion with concentric circumferential calcium (cross-section $>270^{\circ}$ of $\mathrm{CAC}$ ) and a minimal lumen area smaller than the burr size. Complications of RA include burr entrapment, coronary dissection, and perforation but their occurrence can be usually minimized by optimal technique. Fundamental elements of contemporary optimal technique include use of a single burr $(1.5 \mathrm{~mm})$ with burr-to-artery ratio of 0.6 , rotational speed of about 140,000 to $180,000 \mathrm{rpm}$, gradual burr advancement using a pecking motion, short ablative runs ( 15 to $20 \mathrm{~s}$ ), and avoidance of decelerations $>5000 \mathrm{rpm}$. However, in lesions not crossable with a $1.5-\mathrm{mm}$ burr or in very long tortuous segments; a $1.25-\mathrm{mm}$ burr with stepwise escalation may be necessary. [38]
ROTAXUS (Rotational Atherectomy Prior to Taxus Stent Treatment for Complex Native Coronary Artery Disease) [39] trial failed to demonstrate a superiority of RA versus conventional balloon dilatation before DES implantation in heavy CAC. Upfront high-speed RA is feasible in nearly all patients and improves the success of DES deployment compared with modified cutting or scoring balloons, according to results of the contemporary Comparison of Strategies to PREPARE Severely CALCIFIED Coronary Lesions (PREPARE-CALC) trial. Although both strategies ensure equal safety and efficacy, the use of RA is no longer associated with excessive late lumen loss in the modern era. [40]

\subsubsection{Orbital atherectomy}

Orbital atherectomy (OA) is another novel treatment modality for heavy CAC. [31] It consists of an eccentrically mounted diamond-coated 1.25$\mathrm{mm}$ crown, connected to a drive shaft and to a controller powered by a pneumatic console (CSI Diamond $360^{\circ}$ Coronary Orbital Atherectomy System, St. Paul, Minnesota). Compared with the rotaburr, which only allows calcium ablation during forward advancement, the crown of OA with diamond chips both on front and back, enables bidirectional atheroablation (Table 4). 


\begin{tabular}{|c|c|c|c|}
\hline & Rotational atherectomy & Orbital atherectomy & $\begin{array}{c}\text { Excimer laser coronary } \\
\text { atherectomy }\end{array}$ \\
\hline Device & -Rotablator & •Diamondback 360 & $\cdot \mathrm{CVX}-300$ \\
\hline Available sizes & $\begin{array}{l}\cdot 1.25,1.5,1.75,2.0,2.25, \\
2.38, \text { and } 2.5\end{array}$ & $\cdot 1.25 \mathrm{~mm}$ & $\bullet 0.9,1.4,1.7,2.0 \mathrm{~mm}$ \\
\hline $\begin{array}{l}\text { Guide catheter } \\
\text { compatibility }\end{array}$ & $\bullet<1.75 \mathrm{~mm}$ burrs: $6 \mathrm{Fr}$ guide & $\cdot 6 \mathrm{Fr}$ guide & $\begin{array}{l}\cdot 0.9 \text { and } 1.4 \mathrm{~mm}: 6 \mathrm{Fr} \text { guide } \\
1.7 \mathrm{~mm}: 7 \mathrm{Fr} \\
2.0 \mathrm{~mm}: 8 \mathrm{Fr}\end{array}$ \\
\hline Guidewire & $\begin{array}{l}\bullet 0.009 " \text { floppy or extra- } \\
\text { support Rotawire }\end{array}$ & $\begin{array}{l}\bullet 0.012 " / 0.014 " \text { VIPERWIRE } \\
\text { advanced coronary guidewire }\end{array}$ & $\begin{array}{l}\bullet 0.014 " \text { workhorse } \\
\text { guidewire }\end{array}$ \\
\hline Flush solution & $\begin{array}{l}\text {-Rotaglide infusion } \\
\text { under a pressure bag } \\
\text { •Alternative: heparin, } \\
\text { nitroglycerin, and } \\
\text { verapamil in normal saline }\end{array}$ & $\begin{array}{l}\text {-ViperSlide, standard } \\
\text { infusion rate }\end{array}$ & $\begin{array}{l}\text { - Normal saline flush and } \\
\text { infusion, } 1-2 \mathrm{~mL} / \mathrm{s} \\
\text {-Contrast for underexpanded } \\
\text { stents }\end{array}$ \\
\hline Mechanism of actions & $\begin{array}{l}\text {-Rotational } \\
\text {-Diamond-tipped burr spins } \\
\text { concentrically on the wire } \\
\text {-Atheroablation via } \\
\text { differential cutting } \\
\text {-Particle size (5-10um) }\end{array}$ & $\begin{array}{l}\text { - Orbital } \\
\cdot \text { Eccentrically mounted } \\
\text { diamond coated crown uses } \\
\text { centrifugal force } \\
\text { - Atheroablation via } \\
\text { differential sanding } \\
\cdot \text { Particle size }(<2 \text { um) }\end{array}$ & $\begin{array}{l}\text { - Laser } \\
\cdot \text { Multifiber laser catheters } \\
\text { transmit } \\
\text { ultraviolet energy } \\
\text {-Photoablation } \\
\text { (vaporization) } \\
\text {-Particle size }(<10 \mathrm{um})\end{array}$ \\
\hline Technical features & $\begin{array}{l}\cdot \text { Front-cutting unidirectional } \\
\text { burr } \\
\text { •Speed: } 140000-180000 \mathrm{rpm} \text {, } \\
\text { avoid deceleration }>5000 \\
\text { rpm } \\
\text {-Burr movement with } \\
\text { pecking motion/short } \\
\text { ablative runs }(<25 \mathrm{sec})\end{array}$ & $\begin{array}{l}\text {-Diamond coated crown, } \\
\text { bidirectional } \\
\text {-Speed: } 80000-120000 \mathrm{rpm}, \\
\text { larger ablative arc with } \\
\text { higher speed } \\
\text {-Continuous slow forward \& } \\
\text { backward crown movement }\end{array}$ & $\begin{array}{l}\cdot \text { OTW \& rapid exchange } \\
\text { catheters } \\
\text {-Adjustable setting, auto } \\
\text { deactivation after } 5 \mathrm{~s} \text { with a } \\
10 \text {-s pause } \\
\text {-Slow advancement through } \\
\text { lesion }(0.5 \mathrm{~mm} / \mathrm{sec})\end{array}$ \\
\hline $\begin{aligned} \text { Cons } & \\
> & \text { Learning curve } \\
> & \text { Perforation } \\
> & \text { Slow/no-reflow } \\
> & \text { Burr entrapment }\end{aligned}$ & $\begin{array}{l}\text { Long } \\
\text { Moderate } \\
\text { Moderate } \\
\text { Moderate }\end{array}$ & $\begin{array}{l}\text { Short } \\
\text { Low } \\
\text { Low } \\
\text { Crown entrapment unlikely }\end{array}$ & $\begin{array}{l}\text { Short } \\
\text { Low } \\
\text { Low } \\
\text { - }\end{array}$ \\
\hline
\end{tabular}

Table 4: Comparison of various ablative techniques

The crown entrapment is less likely as compared to burr entrapment due to retrograde ablation. The crown is advanced over a dedicated (ViperWire Advance, St. Paul, Minnesota) a 0.014-inchwire, with superior maneuverability compared with the 0.009-inch Rotawire. Using the controller, the operator can move the crown forward and backward and can regulate the speed of the crown orbit (80,000 to $120,000 \mathrm{rpm})$. OA incorporates centrifugal forces which pushes and compresses the crown against the plaque with a "sanding" action of the calcified component. OA might have a selective action on the rigid calcified component, whereas healthy elastic tissue may be spared. Whereas the RA burr is moved forward in a slow, pecking motion to allow intermittent ablation; the OA crown is advanced with a gradual, continuous motion, even interrupting in a region of interest to permit more time for ablation. Notably, by increasing its orbit as rotational speed increases, OA allows ablation of CAC using the same device (1.25-mm crown) in vessels up to $3.5-\mathrm{mm}$ diameter. Other advantages of $\mathrm{OA}$ include the $6-\mathrm{F}$ guiding catheter compatibility, smaller size of particles released during ablation ( 2 vs. 5 to $10 \mathrm{~mm}$ in RA), no interruption in blood flow during crown orbiting, and less vascular heating.
The OA System in treating de novo calcified coronary lesions (ORBIT 1), a prospective, single arm study demonstrated device success in $98 \%$ (defined a residual stenosis $<50 \%$ after $\mathrm{OA}$ ) and procedural success (defined as residual stenosis $<20 \%$ after stenting) in $94 \%$ patients with denovo calcified plaque. It showed dissections without sequelae in $12 \%$ of cases but did not reveal any case of slow/no reflow following OA. [41] The ORBIT II study [42] further confirmed the preliminary results of the ORBIT I in a larger cohort of patients demonstrating device success of $98.6 \%$ and procedural success of $91.4 \%$, with $2.3 \%$ rate of severe coronary dissections. The ongoing, randomized Evaluation of Treatment Strategies for Severe Calcific Coronary Arteries: Orbital Atherectomy vs. Conventional Angioplasty Technique Prior to Implantation of DrugEluting StEnts: The ECLIPSE Trial (ECLIPSE) [NCT03108456, CLN0011-P] is further likely to evaluate OA compared to conventional balloon angioplasty for the treatment of severely calcified lesions prior to DES implantation.

\subsubsection{Excimer laser coronary atherectomy}


Excimer laser coronary atherectomy (ELCA) utilizes photochemical, photothermal and photomechanical mechanisms to ablate heavy CAC. The microparticles released $(<10 \mu \mathrm{m})$ avoid microvascular obstruction as they are absorbed by the reticulo-endothelial system. ${ }^{43}$ The CVX-300 system (Spectranetics, Colorado Springs, CO) emits pulses of ultraviolet light at $308 \mathrm{~nm}$ wavelengths; the generated ultraviolet pulses only penetrate tissue depths of $50 \mathrm{um}$ and therefore lead to relatively pure plaque disintegration without inflicting injuries at the deeper medial or adventitial layers. ELCA catheters are available in four diameters, which are compatible with 6, 7 and 8 Fr catheters; 6 Fr: 0.9 and 1.4, 7 Fr: 1.7 and $8 \mathrm{Fr}: 2.0 \mathrm{~mm}$, based on a catheter:vessel diameter ratio of $0.5: 0.6$, and are compatible with a 0.014 inch guidewire. In the context of CAC, The use of ELCA is limited to that of a 'bail-out' strategy in lesions uncrossable for dedicated balloons or for the RotaWire or ViperWire. The feasibility and efficacy of combining laser to facilitate RA has been described and referred as the RASER technique. [44] The main application of this technique remains in the treatment of calcific undilatable in-stent restenosis, with positive results reported in a recent OCT study. [45]

\section{Conclusion}

The ominous problem of heavy CAC is likely to increase in near future because of an aging population and increased rates of diabetes and chronic renal disease. This may further impose clinical and technical complexity to PCI. In contemporary practice, the optimal therapy for significant CAC is multi-adjunctive and requires the availability of several modalities including intracoronary imaging in the catheterization lab (Figure 4).

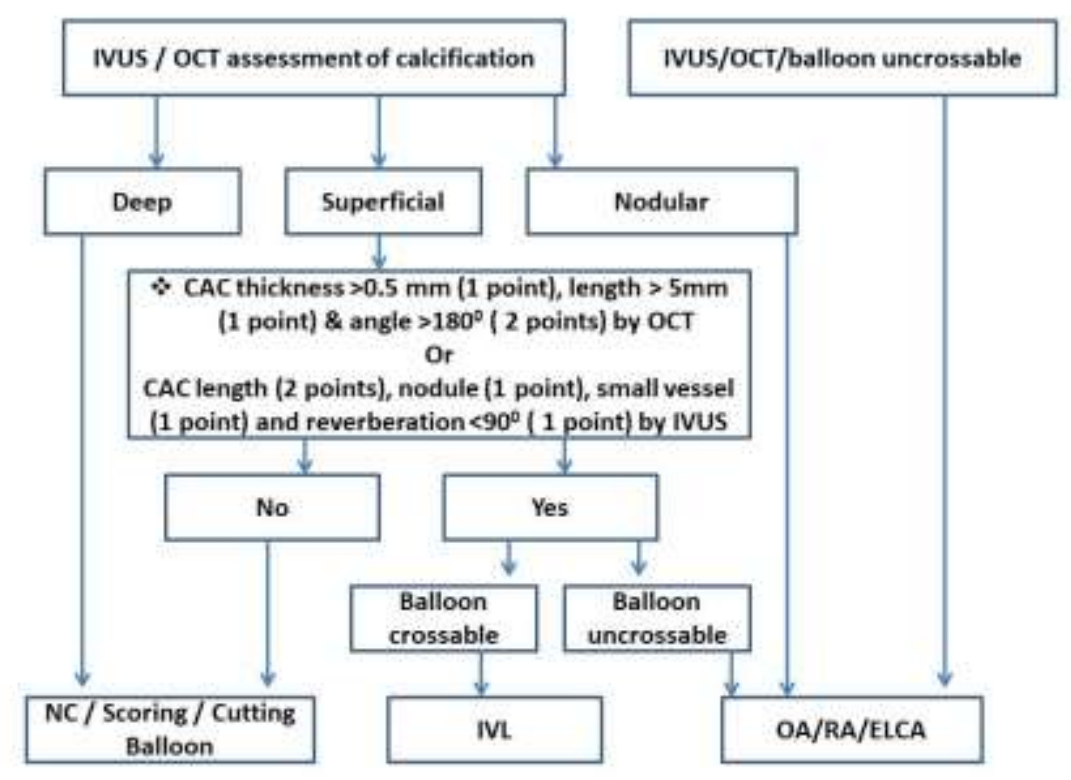

CAC, Coronary artery calcium; ELCA, Excimer laser coronary atherectomy; IVL, Intravascular lithotripsy; IVUS, Intravascular ultrasound; NC, non-compliant balloon; OA, orbital atherectomy; OCT: Optical coherence tomography.

CAC score of 4 in OCT or $\geq 2$ in IVUS is a reliable indicator of stent underexpansion

Figure 4: Proposed algorithm for treatment of calcified coronary lesions

For moderate degree of CAC, the lesion preparation could be achieved with balloon-based approaches. Conversely, higher degree of CAC may require more aggressive ablative approaches, such as ELCA, RA or OA. Because of its ease of use, shorter learning curve, and unique action on both superficial and deep CAC, IVL has the potential of more widespread adoption. The authors feel that there would be a surge in a hybrid approach involving drill (RA or OA) and shock (IVL) in near future. Despite the growing data for various modalities, additional randomized controlled trials are warranted to further clarify the superiority of one modality over another.

\section{List of abbreviations}

CAC, coronary artery calcium; CAG, coronary angiography; CCTA, Coronary computed tomography angiography; ELCA, excimer laser coronary atherectomy; IVL, Intravascular lithotripsy; IVUS, intravascular ultrasound; MACE, major adverse cardiac events; NC, non-complaint; OA, orbital atherectomy; OCT, optical coherence tomography; OTW, over-the-wire; RA, rotational atherectomy; TLR, target lesion revascularization

\section{Declarations}

Ethics approval and consent to participate: Not applicable

Consent for publication: Not applicable 
Availability of data and material: Not applicable

Competing interests: None

Funding: Nil

\section{Authors' contributions}

All authors have read and approved the manuscript

DD: Conception, design of the work, the acquisition, analysis, interpretation of data, draft, revision

SR: Conception, the acquisition, analysis, revision

RM: Analysis, interpretation of data, revision

SAM: Conception, analysis, revision

Acknowledgements: Nil

\section{Reference}

1. ReferencesSharma SK, Israel DH, Kamean JL, et al. JA. Clinical, angiographic, and procedural determinants of major and minor coronary dissection during angioplasty. Am Heart J. 1993;126:39-47.

2. Kawaguchi R, Tsurugaya H, Hoshizaki H, et al. Impact of lesion calcification on clinical and angiographic outcome after sirolimus eluting stent implantation in real-world patients. Cardiovasc Revasc Med. 2008;9:2-8.

3. Rathore S, Terashima M, Katoh O, et al. Predictors of angiographic restenosis after drug eluting stents in the coronary arteries: contemporary practice in real world patients. EuroIntervention. 2009;5:349-354.

4. Onuma Y, Tanimoto S, Ruygrok P, et al. Efficacy of everolimus eluting stent implantation in patients with calcified coronary culprit lesions: two-year angiographic and three-year clinical results from the SPIRIT II study. Catheter Cardiovasc Interv. 2010;76:634-642.

5. Fitzgerald PJ, Ports TA, Yock PG. Contribution of localized calcium deposits to dissection after angioplasty. An observational study using intravascular ultrasound. Circulation. 1992;86:6470 .

6. Kang SJ, Mintz GS, Park DW, et al. Mechanisms of instent restenosis after drug-eluting stent implantation: intravascular ultrasound analysis. Circ Cardiovasc Interv. 2011;4(1):9-14.

7. Fujii K, Carlier SG, Mintz GS, et al. Stent underexpansion and residual reference segment stenosis are related to stent thrombosis after sirolimus eluting stent implantation: an intravascular ultrasound study. J Am Coll Cardiol. 2005;45:995998.
Andrews J, Psaltis PJ, Bartolo BAD, et al. Coronary arterial calcification: a review of mechanisms, promoters and imaging. Trends Cardiovasc Med 2018;28:491-501.

9. Benenati S, De Maria GL, Scarsini R, et al. Invasive "in the cath-lab" assessment of myocardial ischemia in patients with coronary artery disease: when does the gold standard not apply? Cardiovasc Revasc Med 2018;19:362-372.

10. Madhavan MV, Tarigopula M, Mintz GS,et al. Coronary artery calcification: pathogenesis and prognostic implications. J Am Coll Cardiol 2014;63:1703-1714.

11. Généreux P, Madhavan MV, Mintz GS, et al. Ischemic outcomes after coronary intervention of calcified vessels in acute coronary syndromes. Pooled analysis from the HORIZONS-AMI (Harmonizing Outcomes With Revascularization and Stents in Acute Myocardial Infarction) and ACUITY (Acute Catheterization and Urgent Intervention Triage Strategy) TRIALS. J Am Coll Cardiol 2014;63:1845-1854.

12. Nakahara T, Dweck MR, Narula N, et al. Coronary artery calcification: from mechanism to molecular imaging. JACC Cardiovasc Imaging 2017;10:582593.

13. Mintz GS. Intravascular imaging of coronary calcification and its clinical implications. J Am Coll Cardiol Img 2015;8:461-471.

14. Busse A, Cantré D, Beller E, et al. Cardiac CT: why, when, and how: update 2019. Radiologe. 2019.

15. Youssef G, Kalia N, Darabian S et al. Coronary calcium: new insights, recent data, and clinical role. Curr Cardiol Rep 2013;15:325.

16. Mintz GS, Popma JJ, Pichard AD, et al. Patterns of calcification in coronary artery disease. A statistical analysis of intravascular ultrasound and coronary angiography in 1155 lesions. Circulation 1995;91:1959-1965.

17. Liu W, Zhang Y, Yu CM et al. Current understanding of coronary artery calcification. J Geriatr Cardiol. 2015; 12: 668-675.

18. Zhang M, Matsumura M, Usui E, et al. IVUS predictors of stent expansion in severely calcified lesions. J Am Coll Cardiol. 2019 Oct, 74 (13 Supplement) B5.

19. Tearney GJ, Regar E, Akasaka T, et al., International Working Group for Intravascular Optical Coherence Tomography (IWG-IVOCT). Consensus standards for acquisition, measurement, and reporting of intravascular optical coherence tomography studies: a report from the International Working Group for Intravascular Optical Coherence Tomography Standardization and Validation. J Am Coll Cardiol 2012;59:1058-1072.

20. Mehanna E, Bezerra HG, Prabhu D, et al. Volumetric characterization of human coronary calcification by frequency-domain optical coherence tomography. Circ J 2013;77:2334-2340.

21. Fujino A, Mintz GS, Mastumura M, et al. A new optical coherence tomography-based calcium scoring system to predict stent underexpansion. EuroIntervention 2018;13:e2182-e2189. 
22. Secco GG, Ghione M, Mattesini A, et al. Very highpressure dilatation for undilatable coronary lesions: indications and results with a new dedicated balloon. EuroIntervention 2016;12:359-365.

23. Dash D, Ahmed N, Mody R. Contemporary treatment options for surmounting the conundrum of calcified coronaries. J Transcat Intervent.2020;28:eA202007.

24. Mauri L, Bonan R, Weiner BH, et al. Cutting balloon angioplasty for the prevention of restenosis: results of the Cutting Balloon Global Randomized Trial. Am J Cardiol 2002; 90:1079-1083.

25. Okura H, Hayase M, Shimodozono S, REDUCE Investigators. Restenosis Reduction by Cutting Balloon Evaluation Mechanisms of acute lumen gain following cutting balloon angioplasty in calcified and noncalcified lesions: an intravascular ultrasound study. Catheter Cardiovasc Interv 2002;57:429-436.

26. De Maria GL, Scarsini R, Banning AP. Management of calcific coronary artery lesions: Is it time to change our interventional therapeutic approach? JACC Cardiovasc interv. 2019;12:1465-1478.

27. Otsuka Y, Koyama T, Imoto Y, et al. Prolonged inflation technique using a scoring balloon for severe calcified lesion. Int Heart J. 2017; 58(6): 982-987.

28. Brinton TJ, Ali ZA, Hill JM, et al. Feasibility of shockwave coronary intravascular lithotripsy for the treatment of calcified coronary stenoses. Circulation 2019;139:834-836

29. Yeoh J, Hill JM. Intracoronary lithotripsy for the treatment of calcified plaque. Intervent Cardiol Clin 2019;8:411-424.

30. Venuti G, D’Agosta G, Tamburino C, La Manna A. Coronary lithotripsy for failed rotational atherectomy, cutting balloon, scoring balloon, and ultra-high-pressure non-compliant balloon. Catheter Cardiovasc Interv 2019;94:E111-5. https://doi. org/10.1002/ccd.28287; PMID: 31020765s.

31. Chen G, Zrenner B, Pyxaras SA. Combined rotational atherectomy and intravascular lithotripsy for the treatment of severely calcified in-stent neoatherosclerosis: a mini-review. Cardiovasc Revasc Med 2018;20:819-821.

32. Vainer J, Lux A, Ilhan M, et al. Smart solution for hard times: successful lithoplasty of an undilatable lesion. Neth Heart J 2019;27:216-217.

33. Kassimis G, Raina T, Kontogiannis N, et al. How should we treat heavily calcified coronary artery disease in contemporary practice? From atherectomy to intravascular lithotripsy. Cardiovasc Revasc Med 2019.

34. Simsek C, Vos J, IJsselmuiden A. Coronary artery perforation after shockwave intravascular lithotripsy. JACC: Case Report 2020;2:247-249.

35. Ali ZA, Nef H, Escaned J, et al. Safety and effectiveness of coronary intravascular lithotripsy for treatment of severely calcified coronary stenoses: The Disrupt CAD II study. Circ Cardiovasc Interv.
2019

Oct;12(10):e008434.

doi: 10.1161/CIRCINTERVENTIONS.

36. Kawamoto H, Latib A, Ruparelia N, et al. Planned versus provisional rotational atherectomy for severe calcified coronary lesions: insights from the ROTATE multi-center registry. Catheter Cariovasc Interv.2016;88:881-889.

37. van Gaal WJ, Banning AP. Percutaneous coronary intervention and the no-reflow phenomenon. Expert Rev Cardiovasc Ther 2007;5:715-731.

38. Mehanna E, Abbott JD, Bezerra HG. Optimizing percutaneous coronary intervention in calcified lesions: insights from optical coherence tomography of atherectomy. Circ Cardiovasc Interv 2018;11:e006813.

39. Dash D. Percutaneous coronary rotational atherectomy: Does it make sense in 2018? Journal of Indian College of Cardiology 2018;8: 80-86.

40. Abdel-Wahab M, Richardt G, Joachim Büttner H, et al. High-speed rotational atherectomy before paclitaxel-eluting stent implantation in complex calcified coronary lesions: the randomized ROTAXUS (Rotational Atherectomy Prior To Taxus Stent Treatment For Complex Native Coronary Artery Disease) trial. JACC Cardiovasc Interv. 2013;6:10-9.

41. Abdel-Wahab M, Toelg R, Byrne R, et al. High speed rotational atherectomy versus modified balloons prior to drug-eluting stent implantation in severely calcified coronary lesions. Circ Cardiovasc Interv 2018;11:e007415.

42. Parikh K, Chandra P, Choksi N, et al. Safety and feasibility of orbital atherectomy for the treatment of calcified coronary lesions: the ORBIT I trial. Catheter Cardiovasc Interv.2013; 81:1134-1139.

43. Chambers JW, Feldman RL, Himmelstein SI, et al. Pivotal trial to evaluate the safety and efficacy of the orbital atherectomy system in treating de novo, severely calcified coronary lesions (ORBIT II). J Am Coll Cardiol Intv 2014;7:510-518.

44. Badr S, Ben-Dor I, Dvir D, et al. The state of the excimer laser for coronary intervention in the drugeluting stent era. Cardiovasc Revasc Med 2013; 14: 93-98.

45. Fernandez JP, Hobson AR, McKenzie D, et al. Beyond the balloon: excimer coronary laser atherectomy used alone or in combination with rotational atherectomy in the treatment of chronic total occlusions, non-crossable and nonexpansible coronary lesions. EuroIntervention 2013;9:243-250.

46. Lee T, Shlofmitz RA, Song L, et al. The effectiveness of excimer laser angioplasty to treat coronary in-stent restenosis with peri-stent calcium as assessed by optical coherence tomography. EuroIntervention 2019;15:e279-288. 
This work is licensed under Creative Commons Attribution 4.0 License

To Submit Your Article Click Here: Submit Manuscript

DOI:10.31579/2641-0419/139
Ready to submit your research? Choose Auctores and benefit from:

* fast, convenient online submission

* rigorous peer review by experienced research in your field

* rapid publication on acceptance

* authors retain copyrights

* unique DOI for all articles

* immediate, unrestricted online access

At Auctores, research is always in progress.

Learn more www.auctoresonline.org/journals/clinical-cardiology-andcardiovascular-interventions 